\title{
CARBON DIOXIDE SEQUESTRATION BY AQUEOUS MINERAL CARBONATION OF MAGNESIUM SILICATE MINERALS
}

\author{
S. J. Gerdemann, D. C. Dahlin, W. K. O’Connor \& L. R. Penner \\ Albany Research Center \\ Office of Fossil Energy, US DOE \\ 1450 Queen Ave SW \\ Albany, OR, 97321
}

\begin{abstract}
The dramatic increase in atmospheric carbon dioxide since the Industrial Revolution has caused concerns about global warming. Fossil-fuel-fired power plants contribute approximately one third of the total human-caused emissions of carbon dioxide. Increased efficiency of these power plants will have a large impact on carbon dioxide emissions, but additional measures will be needed to slow or stop the projected increase in the concentration of atmospheric carbon dioxide. By accelerating the naturally occurring carbonation of magnesium silicate minerals it is possible to sequester carbon dioxide in the geologically stable mineral magnesite $\left(\mathrm{MgCO}_{3}\right)$. The carbonation of two classes of magnesium silicate minerals, olivine $\left(\mathrm{Mg}_{2} \mathrm{SiO}_{4}\right)$ and serpentine

$\left(\mathrm{Mg}_{3} \mathrm{Si}_{2} \mathrm{O}_{5}(\mathrm{OH})_{4}\right)$, was investigated in an aqueous process. The slow natural geologic process that converts both of these minerals to magnesite can be accelerated by increasing the surface area, increasing the activity of carbon dioxide in the solution, introducing imperfections into the crystal lattice by high-energy attrition grinding, and in the case of serpentine, by thermally activating the mineral by removing the chemically bound water. The effect of temperature is complex because it affects both the solubility of carbon dioxide and the rate of mineral dissolution in opposing fashions. Thus an optimum temperature for carbonation of olivine is approximately $185^{\circ} \mathrm{C}$ and $155^{\circ} \mathrm{C}$ for serpentine. This paper will elucidate the interaction of these variables and use kinetic studies to propose a process for the sequestration of the carbon dioxide.
\end{abstract}

\section{INTRODUCTION}

Burning fossil fuels inevitably produces one $\mathrm{CO}_{2}$ molecule for every carbon atom burned. Traditionally $\mathrm{CO}_{2}$ has not been considered a pollutant because it is already present in the atmosphere. However, the concentration of $\mathrm{CO}_{2}$ in the earth's atmosphere has been increasing and this has been linked to global warming which in turn has led to international calls for the reduction of $\mathrm{CO}_{2}$ emissions. Fossil-fuel-fired power plants account for approximately one third of the total $\mathrm{CO}_{2}$ emissions. Because burning carbon must yield $\mathrm{CO}_{2}$, it is impossible to modify fossil-fuel-fired power plants to stop producing $\mathrm{CO}_{2}$. Therefore, if $\mathrm{CO}_{2}$ emissions from fossilfuel-fired power plants are to be reduced, the $\mathrm{CO}_{2}$ produced must be captured and stored. Proposed methods to sequester $\mathrm{CO}_{2}$ include terrestrial and ocean sequestration, geological sequestration, and mineral carbonation.

Aqueous mineral carbonation reactions take advantage of the natural alteration of ultramafic rocks called serpentinization. When formation waters contact ultramafic rocks, usually at high 
pressure and moderate temperatures, alteration to the hydrated magnesium silicate, serpentine, occurs (eq. 1). When these waters contain dissolved $\mathrm{CO}_{2}$, magnesite may form as a secondary alteration mineral.

$$
2 \mathrm{Mg}_{2} \mathrm{SiO}_{4}+\mathrm{CO}_{2}(\mathrm{~g})+2 \mathrm{H}_{2} \mathrm{O} \Rightarrow \mathrm{Mg}_{3} \mathrm{Si}_{2} \mathrm{O}_{5}(\mathrm{OH})_{4}+\mathrm{MgCO}_{3} \quad 16.5 \mathrm{Kcal}
$$

By increasing the $\mathrm{CO}_{2}$ activity it is possible to form magnesite and no serpentine (eq 2).

$$
\mathrm{Mg}_{2} \mathrm{SiO}_{4}+2 \mathrm{CO}_{2}(\mathrm{~g}) \Rightarrow 2 \mathrm{MgCO}_{3}+\mathrm{SiO}_{2} \quad 10.3 \mathrm{Kcal}
$$

It is also possible to form calcite by a similar reaction (eq. 3).

$$
\mathrm{CaSiO}_{3}+\mathrm{CO}_{2}(\mathrm{~g}) \Rightarrow \mathrm{CaCO}_{3}+\mathrm{SiO}_{2} \quad 10.6 \mathrm{Kcal}
$$

Several important conclusions can be drawn from these equations. All of the reactants and products of equation 1 (olivine, serpentine \& magnesite) can be found in significant quantities in nature and thus under the proper conditions are stable for geologic periods of time. However, both magnesite and serpentine are at a lower thermodynamic state than olivine. Over geologic time most olivine is eventually converted into serpentine and magnesite, and thus serpentine is more prevalent than olivine. Once magnesite has formed, $\mathrm{CO}_{2}$ can be stored indefinitely. This is an important point because, given the very large amount of $\mathrm{CO}_{2}$ that will have to be stored, even a small re-release of $\mathrm{CO}_{2}$ (leak rate) will quickly equal the release from burning fossil fuels. Finally these are geologic reactions and have geologic reaction rates. The challenge is to speed the reaction rate up many orders of magnitude to the point where it can take place in a traditional chemical plant and to do this at minimal capital and energy expense.

Reaction rates can be accelerated by decreasing the particle size, raising the reaction temperature, increasing the pressure, changing the solution chemistry, and using a catalyst. All of these approaches increase the reaction rate and with the proper set of conditions it is possible to accelerate the formation of magnesite or calcite to conversions of over $80 \%$ in less than an hour. However, all these approaches carry energy and/or economic costs.

Thermodynamically these are interesting reactions. Figure 1 is an equilibrium composition calculation using the HSC software. At atmospheric pressure, depending on the temperature, 6 different species can occur: carbonates ( 2 hydrated forms and one non-hydrate), silicates (both olivine and serpentine), and magnesium oxide. At lower temperatures (below $50{ }^{\circ} \mathrm{C}$ ) the hydromagnesites - $\mathrm{MgCO}_{3}\left(\mathrm{H}_{2} \mathrm{O}\right)_{5}, \mathrm{MgCO}_{3}\left(\mathrm{H}_{2} \mathrm{O}\right)_{3}-$ are the major species. As the temperature continues to rise, non-hydrated magnesite becomes more prevalent. Above about $125^{\circ} \mathrm{C}$ magnesite begins to decline and some serpentine appears. As the temperature rises above $200{ }^{\circ} \mathrm{C}$ olivine and $\mathrm{MgO}$ are formed. Raising the pressure extends the region of magnesite stability and suppresses the formation of serpentine and $\mathrm{MgO}$. At 150 atmospheres of $\mathrm{CO}_{2}$, where most test work was done, only 3 species are seen to any appreciable extent: below $100^{\circ} \mathrm{C}$, the two hydrated forms of magnesite, and above $100{ }^{\circ} \mathrm{C}$ only magnesite. 


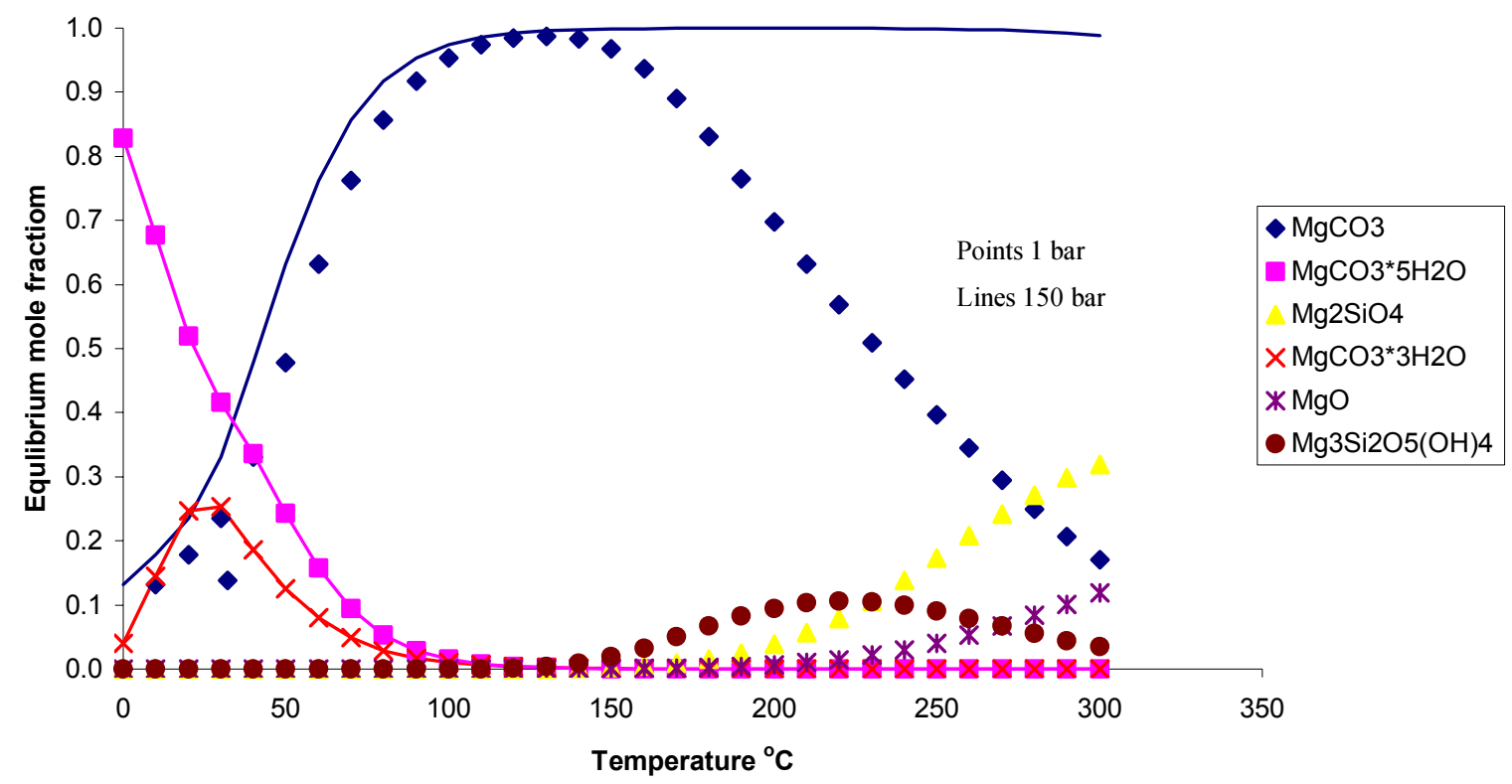

Figure 1: Equilibrium thermodynamic calculation of the $\mathrm{Mg}_{2} \mathrm{SiO}_{4}-\mathrm{CO}_{2},-2 \mathrm{H}_{2} \mathrm{O}$ system.

\section{EXPERIMENTAL PROCEDURE}

All tests were carried out in a two-liter magnetic-stir-drive Hasteloy-C autoclave. In a typical test, a slurry of $167 \mathrm{~g}$ of olivine and $950 \mathrm{ml}$ of $1 \mathrm{M} \mathrm{NaCl}, .64 \mathrm{M} \mathrm{NaHCO}_{3}$ solution were poured into the autoclave ( $15 \%$ solids). The system was purged with $\mathrm{CO}_{2}$ and stirred at $1,000 \mathrm{rpm}$. Then the autoclave was heated to the desired temperature (typically $185^{\circ} \mathrm{C}$ for olivine and $155^{\circ} \mathrm{C}$ for serpentine). After allowing 1 hour for heat up to the operating temperature, $\mathrm{CO}_{2}$ was injected using a gas booster pump to achieve the desired $\mathrm{CO}_{2}$ partial pressure (typically $150 \mathrm{~atm}$ ). The pressure was continuously monitored and more $\mathrm{CO}_{2}$ was injected if the pressure decreased either due to leaks or chemical reaction. At the end of the desired test time the stir rate was decreased to $500 \mathrm{rpm}$ and the slurry was cooled by running water through cooling coils in the solution. When the temperature fell below $85^{\circ} \mathrm{C}$, the pressure was bled off and the slurry removed through a valve in the bottom of the autoclave. The slurry was filtered, and the solids were dried at $105^{\circ} \mathrm{C}$, weighed, and sampled for analysis.

Both olivine and serpentine are attractive mineral reactants for mineral sequestration because of their vast reserves and relatively high magnesium content. The reserves of serpentine are much greater than olivine. Wollastonite does occur in significant quantities but the real extent is less well known.

Three magnesium silicate minerals were chosen for study: Southwest Oregon lizardite (serpentine), Cedar Hill antigorite (serpentine), and Twin Sisters olivine. A limited amount of work was also done on the calcium silicate mineral, wollastonite. Head analyses of the mineral reactants are shown in table 1 . The lower $\mathrm{Mg}$ concentration in the serpentine minerals is due to the presence of $\sim 14 \mathrm{wt}$ pct chemically bound water. $\mathrm{R}_{(\mathrm{CO})}$ represents the ratio of the mass of ore required to carbonate one unit mass of $\mathrm{CO}_{2}$ assuming $100 \%$ conversion of $\mathrm{Fe}^{+2}$, magnesium and 
calcium. The lower $\mathrm{R}_{(\mathrm{CO} 2)}(\sim 1.6)$ for olivine as opposed to serpentine (2.2) means considerably more serpentine would have to be mined to sequester the same amount of $\mathrm{CO}_{2}$. The Twin Sisters deposit in northwest Washington State is estimated to contain over 2 billion tons of unaltered dunite ( $>90 \%$ olivine) enough to carbonate $100 \%$ of the $\mathrm{CO}_{2}$ emissions from $8-101 \mathrm{GW}$ coalfired power plants for $\sim 15$ years. Enough serpentine resources exist in massive ultramafic sequences, or ophiolite belts to sequester all of the $\mathrm{CO}_{2}$ produced from all coal resources.

Table 1 - Head analysis

\begin{tabular}{|l|r|r|r|r|}
\hline & Cedar Hill & \multicolumn{1}{c|}{ SW Oregon } & \multicolumn{1}{c|}{ Twin Sisters } & \\
\hline & \multicolumn{1}{|c|}{ Antigorite } & \multicolumn{1}{c|}{ Lizardite } & \multicolumn{1}{c|}{ Olivine } & Wollastonite \\
\hline & \multicolumn{1}{|c|}{$\%$} & \multicolumn{1}{c}{$\%$} & \multicolumn{1}{c|}{$\%$} \\
\hline $\mathrm{Ca}$ & 0.019 & 0.314 & .0112 & 32.9 \\
\hline $\mathrm{Fe}^{+2}$ & 2.61 & 2.40 & 6.0 & 0.53 \\
\hline $\mathrm{Fe}^{+3}$ & 1.29 & 2.02 & $<.01$ & 001 \\
\hline $\mathrm{Mg}$ & 26.1 & 23.9 & 31.1 & 0.274 \\
\hline $\mathrm{Si}$ & 17.3 & 18.0 & 18.9 & 22.7 \\
\hline Water $^{1}$ & 0.440 & 1.59 & 0.070 & 0.05 \\
\hline $\mathrm{LOI}^{2}$ & 15.1 & 14.8 & 0.390 & 3.23 \\
\hline $\mathrm{R}_{(\mathrm{CO} 2)}{ }^{3}$ & 2.03 & 2.12 & 1.64 & 2.70 \\
\hline
\end{tabular}

1 - Free moisture, measured as the weight loss after 1 hour at $105 \mathrm{C}$, in air.

2 - LOI: Loss on Ignition, measured as the weight loss after 1 hour at $1000 \mathrm{C}$, in argon.

3 - $\mathrm{R}(\mathrm{CO} 2)$ : Ratio of ore mass that must be processed to carbonate 1 unit mass of $\mathrm{CO} 2$, assuming $100 \%$ carbonation of all $\mathrm{Ca}, \mathrm{Fe}+2$, and $\mathrm{Mg}$.

\section{RESULTS}

Figure 2 shows the results of carbonation experiments with olivine, serpentine, and wollastonite. The olivine reaction is consistent with the shrinking particle model $(1,2)$. It is possible to obtain over $90 \%$ carbonation of olivine in 6 hours. In one hour the extent of reaction is similar to heattreated serpentine. However, for shorter periods of time the extent of reaction is less than heattreated serpentine.

Hydomagnesites have never been detected by x-ray diffraction in any test at standard conditions. However, when serpentine is made extremely reactive by attritting the mineral long enough to destroy the crystal structure, it is possible to get substantial carbonation at room temperature. In these limited tests hydromagnesite was detected. This indicates that the magnesite is precipitated during the reaction and not during the cool down. 


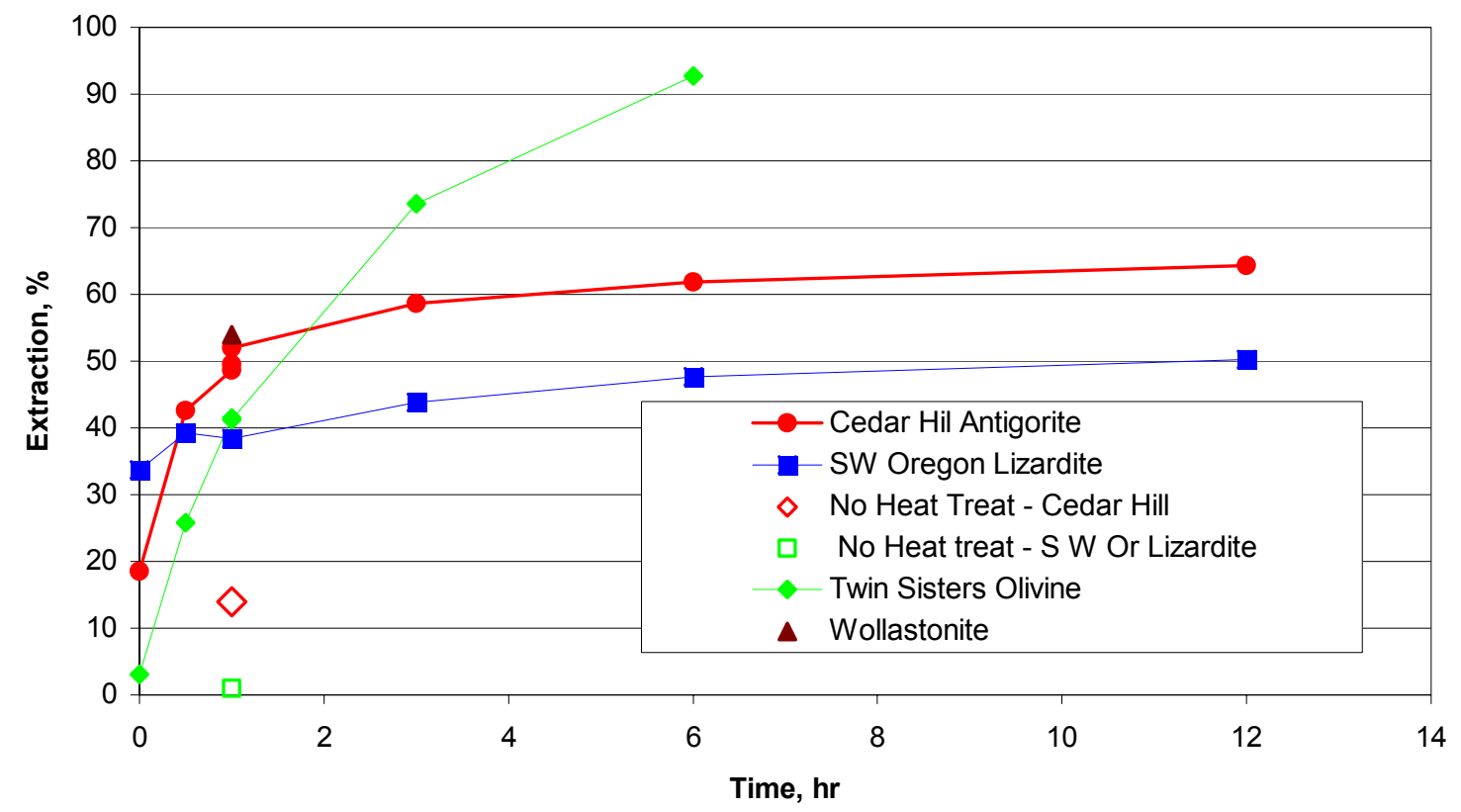

Figure 2: Extraction at $185^{\circ} \mathrm{C}$ and 150 atmospheres

There are significant problems with using serpentine for carbon sequestration. The $\mathrm{R}_{(\mathrm{CO})}$ for serpentine is about 25 to $30 \%$ higher than for olivine and untreated serpentine does not react to any significant extent. Even finely ground serpentine reaches only approximately $10 \%$ carbonation in an hour. At present, two solutions, both expensive, have been found to this problem: heat treatment and high-energy attrition grinding. Heat treatment to remove the chemically bound water takes about 240 kilowatts per ton. After heat treatment, serpentine reacts quickly, reaching approximately $40 \%$ in less than a half hour. However, the maximum conversion is much less than olivine. Heat treatment at $630{ }^{\circ} \mathrm{C}$ for one hour did not remove all the chemically bound water. The remaining water is a good predictor of the maximum conversion.

A limited amount of work has been done on wollastonite. Unlike olivine and serpentine, the extent of reaction for wollastonite is higher in distilled water than in the bicarbonate solution. In the bicarbonate solution, $54 \%$ of the wollastonite carbonated in one hour while in distilled water $72 \%$ carbonated. This is essentially the same as olivine. However the particle size for the wollastonite used was slightly larger than the olivine and thus wollastonite appears to be more reactive than olivine or serpentine. Wollastonite is substantially more reactive in distilled water than olivine in bicarbonate solution. Much work remains to be done on wollastonite to maximize the reaction rate.

Figure 3 shows the effect of raising the reaction temperature from room temperature to $250^{\circ} \mathrm{C}$ on the extent of reaction for Twin Sisters olivine in one hour. The maximum extent of reaction $(50 \%)$ occured at $185^{\circ} \mathrm{C}$. Two factors work against raising the temperature: (1) carbon dioxide solubility decreases, and (2) the reaction becomes thermodynamically less favorable. Thus, above a certain temperature, the extent of reaction decreases. This temperature is approximately $185^{\circ} \mathrm{C}$ for olivine and $155^{\circ} \mathrm{C}$ for heat-treated serpentine. 


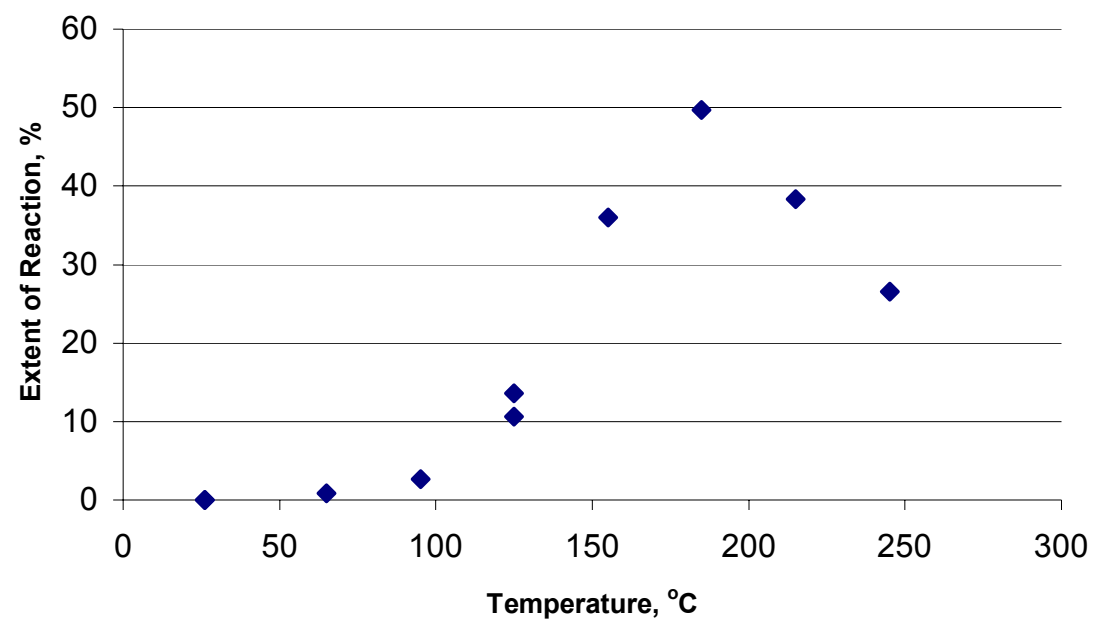

Figure 3: Effect of temperature on carbonation of Twin Sisters olivine

Raising the partial pressure of $\mathrm{CO}_{2}$ also increases the extent of reaction in one hour (figure 4). This is probably due to the increased activity of $\mathrm{CO}_{2}$ however pressure also pushes the reaction towards completion because of the volume change due to the gas consumption as $\mathrm{CO}_{2}$ is converted into solid $\mathrm{MgCO}_{3}$.

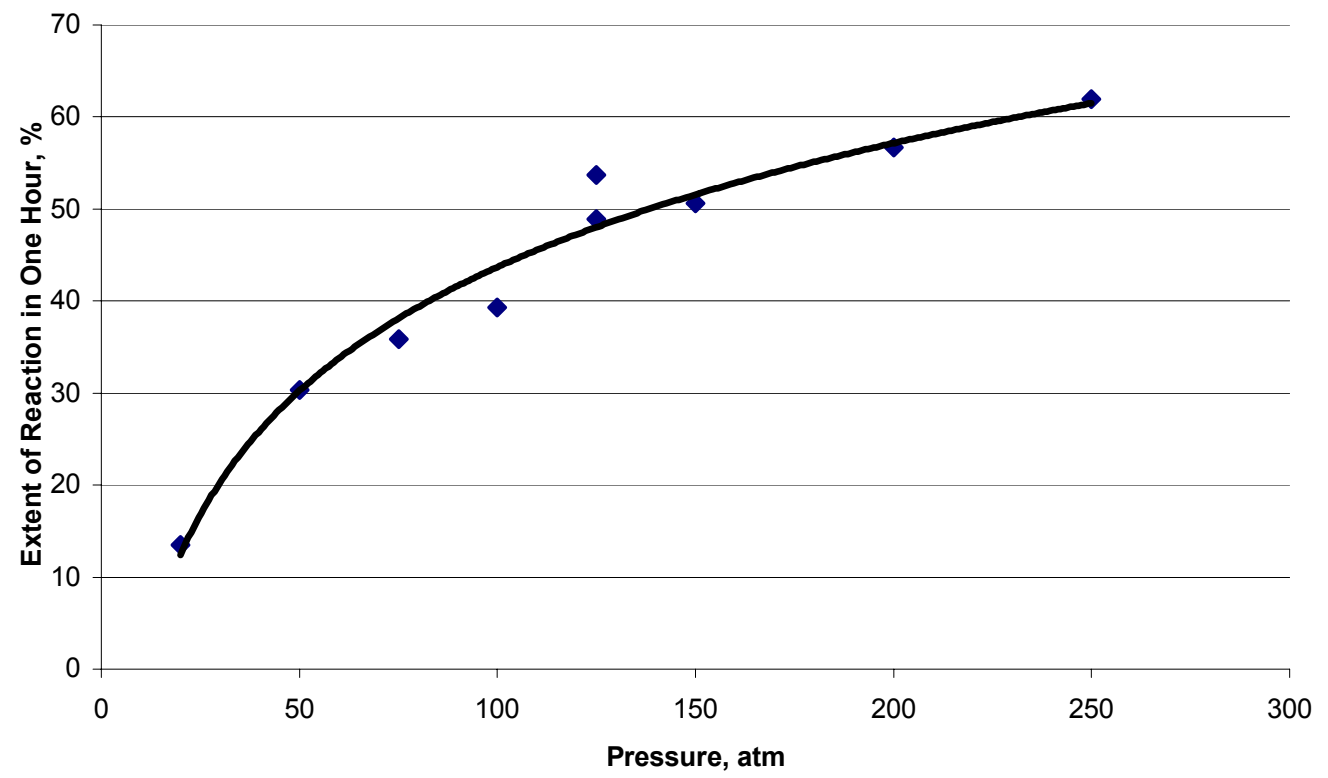

Figure 4: Effect of raising the partial pressure of $\mathrm{CO}_{2}$ at $185{ }^{\circ} \mathrm{C}$.

Initial work was done using standard milling practice to reduce the mineral to less than 75 microns. It is possible to obtain higher reaction rates by further decreasing the particle size. This further size reduction was done in a METSO stirred media detritor (SMD). It is similar to the attriter used in earlier studies (3) but is scaleable and has a power meter for energy measurement. The SMD operates at $555 \mathrm{rpm}$ and is only used to wet mill. 
Figure 5 shows results using the SMD mill. Over the range of these tests extent of reaction was linearly proportional to the energy used. The particle size $\left(\mathrm{D}_{50}\right)$ as determined by a Micromeritics Sedigraph also decreases but not linearly. Using the SMD mill it is possible to achieve $80 \%$ conversions in one hour. This, however, carries a significant energy penalty of 230 kilowatts per ton of ore milled. For comparison it took approximately 240 kilowatts per ton to heat-treat serpentine which only achieved 50\% conversion in an hour.

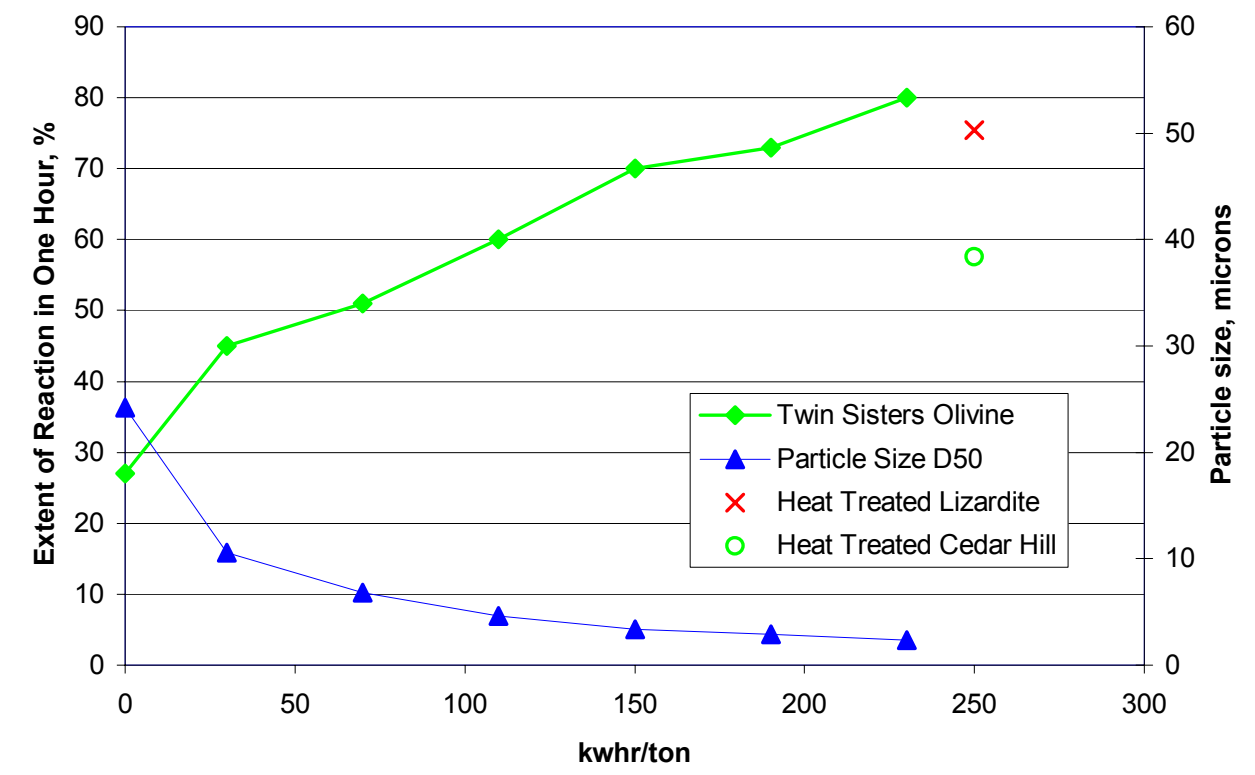

Figure 5: Twin Sisters olivine at $185^{\circ} \mathrm{C}$ and 150 atmospheres $\mathrm{CO}_{2}$.

The results of these experiments were used to design a unique high-pressure flow reactor. This flow reactor is a plug flow reactor that achieves residence time by recirculating the reactants through a loop of $1 / 2$ inch ID pipe many times. A unique high-pressure slurry pump keeps the slurry flowing. The loop reactor contains several static mixers to keep the solids suspended. The pressure drops across the static mixers and the pump continuously monitored by differential pressures transducers, which are displayed and stored on a computer. Conversions in the flow loop reactor will be compared to those obtainable in the autoclave system and then used to design a larger and truly continuous reactor. Initial results achieved the same $80 \%$ conversion in the flow reactor that was achieved in the autoclave.

\section{CONCLUSIONS}

Because magnesite is a geologically stable mineral, carbon sequestration by mineral carbonation is an attractive option for long-term storage of $\mathrm{CO}_{2}$. Several problems remain to be solved before this approach is to be implemented. Serpentine is more prevalent than olivine. There is enough serpentine to sequester all the $\mathrm{CO}_{2}$ produced in a fossil fuel plant. However, serpentine is unreactive without either a prohibitively energy cost for a heat treatment step or an energy intensive attrition grind. Some method must be found to speed up the carbonation of serpentine without heat treatment. Olivine requires no heat treatment but is less common than serpentine. There is however, enough olivine that it could represent a regional solution. Again, the reaction 
needs to be sped up without using too much energy in the feed preparation. Less work has been done on wollastonite but it appears to offer the same advantages and disadvantages as olivine. Wollastonite is probably more reactive than olivine and may not even require the bicarbonate solution to react but is only prevalent enough to represent a regional solution. Further work is needed and some innovative ideas will be required if mineral sequestration is to become a viable solution to the build up of $\mathrm{CO}_{2}$ in the atmosphere.

\section{REFERENCES}

1. Ityokumbul, M.T., Chander, S., O'Connor, W.K., Dahlin, D.C., and Gerdemann, S.J., "Reactor Design Considerations in Mineral Sequestration of Carbon Dioxide," Proc. of the $18^{\text {th }}$ Annual Inter. Pittsburgh Coal Conference, Session 17, Paper 17-4, Newcastle, NSW, Australia, December 3-7, 2001, 9 pp. S. J. Gerdemann, D. C. Dahlin, \& W. K. O’Connor.

2. S. J. Gerdemann, D. C. Dahlin, \& W. K. O'Connor, "Carbon Dioxide Sequestration by Aqueous Mineral Carbonation of Magnesium silicate Minerals," Conference Proceedings GHGT-6 Kyoto Japan Oct 2003.

3. W.K. O’Connor, D.C. Dahlin, D.N. Nielsen, S.J. Gerdemann, G.E. Rush, L.R. Penner, R.P. Walters and P.C. Turner, "Continuing Studies on Direct Aqueous Mineral Carbonation For CO2 Sequestration", The Proceedings of the $27^{\text {th }}$ International Technical Conference on Coal Utilization \& Fuel Systems, March 2002 pp 819-830.

4. O'Connor, W.K., Dahlin, D.C., Rush, G.E., Dahlin C.L., and Collins W.K., "Carbon Dioxide Sequestration by Direct Mineral Carbonation: Process mineralogy of Feed and Products", Minerals \& Metallurgical Processing, Vol. 19 No. 2, pp. 95-101.

5. O’Connor, W.K., Dahlin, D.C., Nilsen, D.N., Rush, G.E., Turner, P.C., and Walters, R.P., " $\mathrm{CO}_{2}$ Storage in Solid Form: A Study of Direct Mineral Carbonation," Proc. of the $5^{\text {th }}$ Inter. Conference on Greenhouse Gas Technologies, Cairns, Australia, August 14-18, 2000, 7 pp. 